\title{
Mempelajari Laju Kerusakan Krim Kunyit - Lidah Buaya (Curcuma domestica Val. - Aloe vera) pada Berbagai Konsentrasi Phenoxyethanol selama Penyimpanan
}

The Study of Damage Rate Tumeric-Aloe vera cream (Curcuma domestica Val. - Aloe vera) on Various Concentrations of Phenoxyethanol During Storage.

\author{
Alfina Via Azizah, Sri Mulyani*, Lutfi Suhendra \\ PS Teknologi Industri Pertanian, Fakultas Teknologi Pertanian, Universitas Udayana, Kampus Bukit \\ Jimbaran, Badung, Kode pos : 80361; Telp/Fax : (0361) 701801
}

Diterima 08 Juni 2021 / Disetujui 06 Juli 2021

\begin{abstract}
This study aimed to: 1) Determine the effect of phenoxyethanol concentrations as a preservative of turmericAloe vera cream. 2) Determine the right phenoxyethanol concentration to produce turmeric-Aloe vera cream with a longer self life and fulfil the requirement of SNI. This study used a Simple Linier Regression. The concentration of phenoxyethanol treatment consisted of 6 levels, namely $0 \% ; 0,2 \% ; 0,4 \% ; 0,6 \% ; 0,8 \%$ and 1\%. Each treatment was repeated 3 times, so that 18 experimental units were obtained. The data was analysed using linier regression to showed the damage rate of turmeric-Aloe vera cream during storage. The variables observed in turmeric-Aloe vera cream are homogeneous, $\mathrm{pH}$, specific gravity, viscosity, total phenol, total plate count, and yeast fungus score. The results of the study showed that the best concentrations of phenoxyethanol is 1\%: homogeneous, pH 5, specific gravity $1,00130 \mathrm{~g} / \mathrm{cm}^{3}$, viscosity $10400 \mathrm{cps}$, total phenol 6,33176 mg GAE/g, ALT 0 koloni/g dan AKK 0 koloni/g and also that is able to keep the physical properties of turmeric-Aloe vera cream in 41-53 weeks and can inhibits microbial growth until 6 weeks.
\end{abstract}

Keywords : turmeric, Aloe vera, preservative, phenoxyethanol

\begin{abstract}
ABSTRAK
Penelitian ini bertujuan untuk mengetahui hubungan konsentrasi phenoxyethanol pada laju kerusakan krim kunyit-lidah buaya serta untuk mengetahui konsentrasi phenoxyethanol yang tepat sehingga mampu menghasilkan krim kunyit-lidah buaya dengan umur simpan yang lebih lama dan memenuhi persyaratan SNI. Penelitian menggunakan model analisis Regresi Linier Sederhana, dengan perlakuan konsentrasi Phenoxyethanol yang terdiri dari 6 taraf yaitu $0 \% ; 0,2 \% ; 0,4 \% ; 0,6 \% ; 0,8 \%$ dan $1 \%$. Perlakuan dikelompokan menjadi 3 kali sehingga, terdapat 18 unit percobaan. Data objektif yang diperoleh dianalisis menggunakan regresi linier untuk mengetahui laju kerusakan krim kunyit-lidah buaya selama masa penyimpanan. Parameter yang diamati pada krim kunyit-lidah buaya yaitu uji homogenitas, uji $\mathrm{pH}$, uji bobot jenis, uji viskotitas, uji total fenolik, uji angka lempeng total (ALT) dan uji kapang khamir (AKK). Hasil penelitian menunjukkan bahwa konsentrasi terbaik konsentrasi pengawet phenoxyethanol yaitu pada perlakuan P6(1\%) dengan nilai pH 5, bobot jenis 1,00130 g/ $\mathrm{cm}^{3}$, viskositas $10400 \mathrm{cps}$, total fenol 6,33176 mg GAE/g, ALT 0 koloni/g dan AKK 0 koloni/g. Serta mampu mempertahankan karakteristik fisik krim kunyit-lidah buaya antara 41-53
\end{abstract}

\footnotetext{
*Korespondensi Penulis:

Email: srimulyani@unud.ac.id
} 
minggu dan mampu menghambat mikroba selama 6 minggu penyimpanan.

Kata kunci : kunyit, lidah buaya, pengawet, phenoxyethanol

\section{PENDAHULUAN}

Kosmetik telah menjadi bagian kehidupan manusia sejak zaman dahulu. Kosmetik digunakan secara luas baik untuk kecantikan maupun untuk kesehatan. Sediaan kosmetik yang umum digunakan untuk perawatan wajah yaitu krim. Salah satu bahan herbal yang bisa digunakan dalam pembuatan krim adalah lidah buaya dan kunyit yang diaplikasikan dalam pembuatan krim. Lidah buaya mengandung senyawa fenolik berupa vitamin $\mathrm{C}$ dan $\mathrm{E}$ yang sangat baik untuk tubuh yang berperan sebagai antioksidan (Morsy, 1991). Menurut Devi et al (2019) pada penelitian krim lidah buaya menunjukkan bahwa krim lidah buaya mengandung senyawa fenolik sebesar 3,02 mg GAE/g. Sedangkan rimpang kunyit merupakan salah satu bahan yang dimanfaatkan sebagai bahan utama dalam produk kosmetik, karena kandungan senyawa fenolik yang berfungsi sebagai anti aging (Mulyani et al., 2017).

Salah satu kekurangan sediaan krim yaitu mudah rusak. Kerusakan sediaan krim biasanya dikarenakan kerusakan emulsi pada sediaan krim, penyimpanan pada suhu yang tidak sesuai serta komposisi krim yang tidak sesuai sehingga zat pengemulsinya tidak dapat tercampur dengan baik (Syamsuni, 2006). Menurut wahyuni (2019) pertumbuhan mikroorganisma dalam suatu sediaan krim juga akan merusak sediaan tersebut malah mungkin mendatangkan resiko kesehatan kepada pengguna seperti infeksi atau iritasi kulit. Krim kunyit-lidah buaya ini mengandung senyawa kurkumin pada kunyit yang mampu menghambat bakteri. Berdasarkan penelitian masa simpan krim kunyit dihasilkan bahwa kunyit memiliki efektifitas penghambatan selama 5 minggu dan jika waktu penyimpanan semakin lama akan mengakibatkan penurunan mutu (Natalie et al, 2017).

Bahan pengawet berperanan untuk memperpanjang jangka waktu sediaan kosmetik dengan memberi perlindungan dari kontaminasi mikrobial semasa penggunaan atau penyimpanan kosmetik. Fungsi utama bahan pengawet dalam sediaan kosmetik adalah untuk mencegah pertumbuhan mikroorganisma semasa kosmetik digunakan dan mengurangi kerusakan kosmetik dari segi perubahan bau atau komposisi (Wahyuni,2019). Untuk menentukan kecepatan kerusakan sediaan krim yang telah ditambahakan bahan pengawet maka perlu diukur laju kerusakannya. Laju kerusakan merupakan suatu fungsi yang menggambarkan kecepatan dari suatu kerusakan yang terjadi pada komponen atau senyawa tertentu (Supriatna et al, 2015).

Salah satu bahan pengawet krim yaitu Phenoxyethanol. Senyawa phenoxyethanl merupakan pengawet yang digunakan dalam berbagai produk perawatan pribadi dan kosmetik serta dengan sensitifitas terhadap kulit yang relative rendah (Kim et al, 2015). Phenoxyethanol mengandung fenol, yang memiliki kemampuan untuk menghambat aktivitas fagositik, memiliki aktivitas antimikroba spektrum luas terhadap mikroba, terutama bakteri gram negatif. (Lawrence $e t$ $a l, 1982)$. Dari hasil survey yang dilakukan telah terbukti bahwa pengawet phenoxyethanol ada pada hampir semua produk yang telah beredar di toko-toko kosmetik Indonesia misalnya Garnier, Wardah, Ponds, Safi, Emina dan masih banyak lagi.

Penelitian ini diharapkan bisa sebagai acuan dalam pemilihan bahan pengawet yang aman dalam pembuatan krim, sehingga krim dapat disimpan dengan dengan umur simpan yang lebih lama serta memenuhi persyaratan SNI. Sehingga krim yang dihasilkan mampu 
bertahan dari kontaminasi mikrobia selama pemasaran, penyimpanan maupun saat penggunaan produk.

\section{METODE PENELITIAN}

\section{Bahan dan Alat}

Bahan-bahan yang digunakan dalam melaksanakan penelitian ini kunyit varietas toleran naungan dan lidah buaya yang di peroleh dari pasar swalayan Tiara Dewata, etanol, asam stearat, virgin coconut oil, setil alkohol, aquades, moistruzer conditioner span 80, tween 80, propilen glikol, sorbitol, gliserin, setil alcohol, parfum, $\mathrm{NaCl} 0,85 \%$, Plate Count Agar (Oxoid), Potato Dekstrosa Agar (PDA), alkohol 70\%.

Peralatan yang digunakan dalam penelitian ini yaitu cawan petri (Iwaki CTE33), gelas beaker (Iwaki CTE33), labu takar (Iwaki CTE33), gelas ukur (Iwaki CTE33), mikropipet (Socorex Swiss), pHmeter (Beckman), Vortex (Barnstead Thermolyne Type 37600 mixer), Viscometer (Brokfield), Centrifuge (Rotofix 32 Hettich), spectrofotometer UV-VIS (Biochrome SN 133467 UV-VIS), B_Mix, neraca analitik (Ohaus) dan peralatan gelas, kertas saring, rotary evaporator, corong, lempeng kaca, gelas objek, tabung reaksi, alumunium foil, kertas Whatman no.1, dan kertas label, tabung durham, neraca analitik (Satorius), oven, pisau, laminar air flow, incubator, tabung reaksi, batang kaca bengkok, (spread), Bunsen.

\section{Pelaksanaan Penelitian}

Pelaksanaan penelitian meliputi persiapan bahan yaitu pembuatan ekstrak kunyit dan ekstrak lidah buaya kemudian dilanjutkan dengan pembuatan sediaan krim. Dalam pembuatan sediaan krim terdapat dua fase yaitu, fase minyak terdiri dari asam stearat, virgin coconut oil (VCO), Span 80, setil alcohol, parfum dan phenoxyethanol. Fase air terdiri dari tween 80, propilen glikol, gliserin, sorbitol, ekstrak lidah buaya konsentrasi $50 \%$ dan ekstrak kunyit konsentrasi 50\%. Fase minyak dipanaskan dengan suhu $65^{\circ} \mathrm{C}$ selama 15 menit pada waterbath hingga melebur serta pemanasan fase air dengan suhu $65^{\circ} \mathrm{C}$ selama 15 menit pada waterbath hingga melebur. Selanjutnya fase air ditambahkan sedikit demi sedikit ke dalam campuran fase minyak sambil melakukan pengadukan dengan menggunakan Ba_mix selama 15 menit hingga homogen dan terbentuknya sediaan krim. Pengujian yang dilakukan yaitu homogenitas, $\mathrm{pH}$, bobot jenis, viskositas, total fenol, Angka Lempeng Total (ALT) dan Angka Kapang Khamir (AKK). Data objektif yang diperoleh dianalisis menggunakan regresi linier.

Tabel 1. Formula krim kunyit-lidah buaya (Mulyani, 2019) dan perlakuan penambahan phenoxyethanol. 


\begin{tabular}{|c|c|c|c|c|c|c|c|}
\hline \multirow[b]{2}{*}{ No. } & \multirow[b]{2}{*}{ Bahan } & \multicolumn{6}{|c|}{ Konsentrasi Phenoxyethanol } \\
\hline & & $\begin{array}{c}\text { P1 } \\
(0 \%)\end{array}$ & $\begin{array}{c}\text { P2 } \\
(0,2 \%)\end{array}$ & $\begin{array}{c}\text { P3 } \\
(0,4 \%)\end{array}$ & $\begin{array}{c}\text { P4 } \\
(0,6 \%)\end{array}$ & $\begin{array}{c}\text { P5 } \\
(0,8 \%)\end{array}$ & $\begin{array}{c}\text { P6 } \\
(1 \%)\end{array}$ \\
\hline 1. & Asam Stearat (g) & 10,9 & 10,9 & 10,9 & 10,9 & 10,9 & 10,9 \\
\hline 2. & Virgin Coconut oil (VCO) (g) & 3,64 & 3,64 & 3,64 & 3,64 & 3,64 & 3,64 \\
\hline 3. & Setil alcohol (g) & 2 & 2 & 2 & 2 & 2 & 2 \\
\hline 4. & Span $80(\mathrm{~g})$ & 3,1 & 3,1 & 3,1 & 3,1 & 3,1 & 3,1 \\
\hline 5. & Tween $80(\mathrm{~g})$ & 2,7 & 2,7 & 2,7 & 2,7 & 2,7 & 2,7 \\
\hline 6. & Moisturizer Conditioner (g) & 10 & 10 & 10 & 10 & 10 & 10 \\
\hline 7. & Parfum (g) & 0,5 & 0,5 & 0,5 & 0,5 & 0,5 & 0,5 \\
\hline 8. & Phenoxyethanol (g) & 0 & 0,2 & 0,4 & 0,6 & 0,8 & 1 \\
\hline 9. & $\begin{array}{l}\text { Penambahan Ekstrak } \\
\text { Lidah Buaya-Kunyit } \\
\text { (1:1) sampai (g) }\end{array}$ & 100 & 100 & 100 & 100 & 100 & 100 \\
\hline
\end{tabular}

\section{Variabel yang Diamati}

Variabel yang diamati pada penelitian ini adalah: Uji Homogenitas, uji pH, uji bobot jenis, uji viskotitas, uji total fenolik, uji angka lempeng total (ALT) dan uji kapang khamir (AKK).

\section{HASIL DAN PEMBAHASAN}

\section{Homogenitas}

Uji homogenitas pada krim bertujuan untuk mengetahui komponen-komponen pada sediaan krim sudah tercampur secara merata. Hasil yang didapatkan berdasarkan pengamatan visual yang telah dilakukan pada sediaan krim kunyit-lidah buaya bahwa seluruh perlakuan menunjukkan hasil yang homogen dan tidak terdapat adanya gumpalan. Hal ini dikarenakan formulasi emulsifier yang tepat serta bahan aktif yang sama, terdispersi dengan baik sehingga sediaan krim menjadi homogen (Devi et al, 2019). Berikut disajikan hasil iji homogenitas krim pada Tabel 2.
Tabel 2. Hasil pengamatan homogenitas

\begin{tabular}{cc}
\hline $\begin{array}{c}\text { Konsentrasi } \\
\text { Phenoxyethanol }\end{array}$ & Hasil Pengamatan \\
\hline P1 $(0 \%)$ & Homogen \\
P2 $(0,2 \%)$ & Homogen \\
P3 $(0,4 \%)$ & Homogen \\
P4 $(0,6 \%)$ & Homogen \\
P5 $(0,8 \%)$ & Homogen \\
P6 $(1 \%)$ & Homogen \\
\hline Sediaan & krim dapat dikatakan
\end{tabular}
homogen jika dioleskan pada sekeping kaca tidak adanya pemisahan antara komponen penyusun emulsi tersebut (Erungan et al, 2009).

\section{pH}

Uji $\mathrm{pH}$ bertujuan untuk mengetahui tingkat keasaman pada sediaan krim sehingga aman digunkan serta tidak mengiritasi kulit (Juwita et al, 2013). Nilai $\mathrm{pH}$ dapat dikatakan sesuai dengan $\mathrm{pH}$ normal kulit yaitu yang berkisar antara 4,5-6,5 (Rizky et al. 2013). Nilai uji $\mathrm{pH}$ selama penyimpanan 6 minggu disajikan pada Gambar1. 


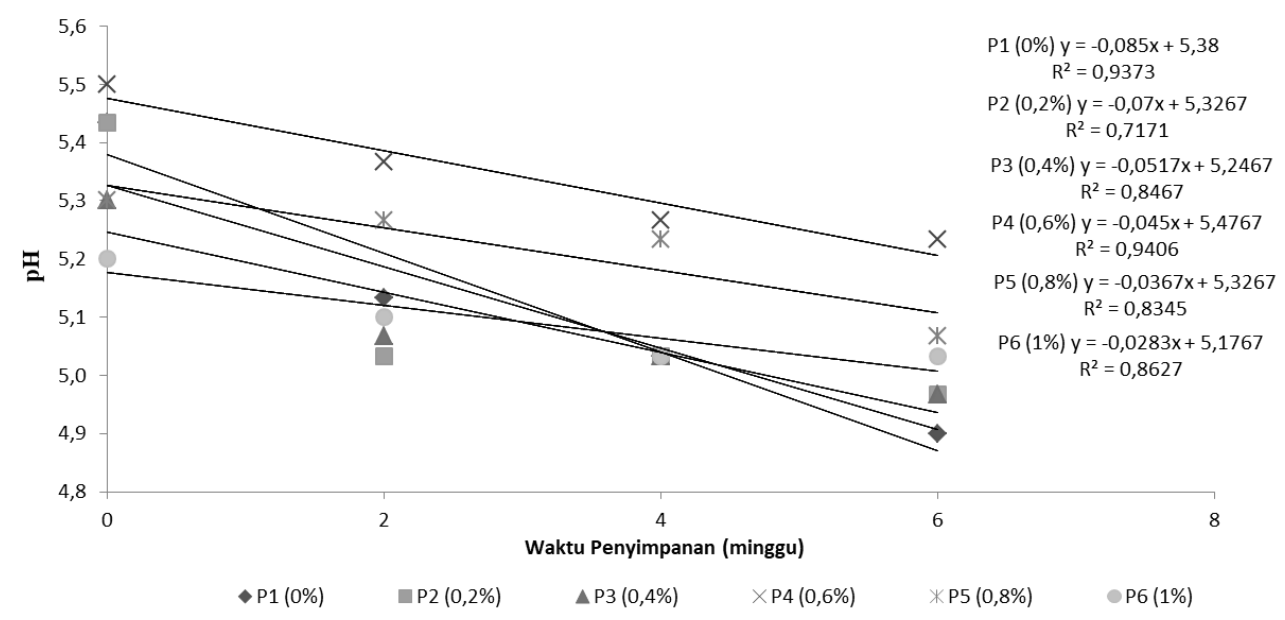

Gambar 1. Grafik pH krim kunyit-lidah buaya selama 6 minggu penyimpanan.

Gambar 1 menunjukkan $\mathrm{pH}$ krim kunyit-lidah buaya selama 6 minggu penyimpana mengalami penurunan. Nilai $\mathrm{pH}$ awal krim pada minggu ke-0 berkisar antara 5,5-5,3 sedangkan pada minggu ke-6 berkisar antara 5,2-4,8. Meskipun $\mathrm{pH}$ selama penyimpanan 6 minggu mengalami penurunan nlai $\mathrm{pH}$ sediaan krim masih memenuhi standar SNI. Hasil regresi linier parameter $\mathrm{pH}$ krim kunyit lidah-buaya dapat dilihat pada Tabel 3 .

Dapat dilihat dari Tabel 3 bahwa koefisien regresi parameter $\mathrm{pH}$ dari variabel lama penyimpanan (X) pada perlakuan $\mathrm{P} 1(0 \%)$ yaitu $-0,085, \mathrm{P} 2(0,2 \%)$ yaitu $-0,07$, $\mathrm{P} 3(0,4 \%)$ yaitu $-0,0517, \mathrm{P} 4(0,6 \%)$ yaitu $0,045, \mathrm{P} 5(0,8 \%)$ yaitu $-0,0367$ dan P6(1\%) yaitu $-0,0283$.

Tabel 3. Persamaan regresi linier parameter $\mathrm{pH}$ krim kunyit-lidah buaya.

\begin{tabular}{ccc}
\hline Perlakuan & Persamaan Regresi & Determinan $\left(\mathrm{R}^{2}\right)$ \\
\hline P1 $(0 \%)$ & $\mathrm{y}=-0,085 \mathrm{x}+5,38$ & 0,9373 \\
P2 $(0,2 \%)$ & $\mathrm{y}=-0,07 \mathrm{x}+5,3267$ & 0,7171 \\
P3 $(0,4 \%)$ & $\mathrm{y}=-0,0517 \mathrm{x}+5,2467$ & 0,8467 \\
P4 $(0,6 \%)$ & $\mathrm{y}=-0,045 \mathrm{x}+5,4767$ & 0,9406 \\
P5 $(0,8 \%)$ & $\mathrm{y}=-0,0367 \mathrm{x}+5,3267$ & 0,8345 \\
P6 (1\%) & $\mathrm{y}=-0,0283 \mathrm{x}+5,1767$ & 0,8627 \\
\hline
\end{tabular}

Dari hasil tersebut dapat diketahui bahwa semakin tingginya penambahan konsentrasi phenoxyethanol dalam sediaan krim kunyitlidah buaya maka akan semakin menghambat laju kerusakan $\mathrm{pH}$ krim. Hal tersebut dikarenakan pengawet phenoxyethanol bekerja pada spektrum $\mathrm{pH}$ yang luas sehingga mampu menjaga kestabilan sediaan krim. Dari hasil persamaan regresi linier P6(1\%) merupakan perlakuan terbaik yang mempunyai laju kerusakan paling rendah. Berdasarkan hasil analisis regresi linier P6(1\%) yang merupakan perlakuan terbaik mempunyai nilai $\mathrm{R}^{2}$ sebesar 0,8627 yang menunjukkan bahwa 86,27\% laju kerusakan dipengaruhi oleh konsentrasi phenoxyethanol dan sisanya dipengaruhi oleh variabel diluar yang diteliti. Penurunan $\mathrm{pH}$ diluar waktu penyimpanan dipengaruhi oleh senyawa fenolik yang mengalami oksidasi serta faktor cahaya dan kelembaban selama penyimpanan (Devi et al, 2019). Pengawet ini bekerja efektif pada rentang $\mathrm{pH}$ yang luas sehingga tidak mempengaruhi stabilitas $\mathrm{pH}$ pada suatu sediaan krim pada berbagai konsentrasi (Rowe at al, 2009).

\section{Bobot Jenis}

Uji bobot jenis pada krim bertujuan untuk menentukan mutu dan melihat kemurnian dari suatu senyawa dalam hal ini khususnya pada krim. Nilai bobot jenis juga dapat digunakan untuk mengetahui kemampuan sediaan untuk dapat di bilas dengan air (Indrawati dan Dovita, 2013). 
Pengukuran bobot jenis dilakukan dengan menggunakan piknometer. Nilai bobot jenis dapat dikatakan sesuai apabila memenuhi standard SNI 16-4399-1996 yang berkisar antara 0,95-1,05 $\mathrm{g} / \mathrm{cm}^{3}$. Nilai uji $\mathrm{pH}$ selama penyimpanan 6 minggu disajikan pada Gambar 2.

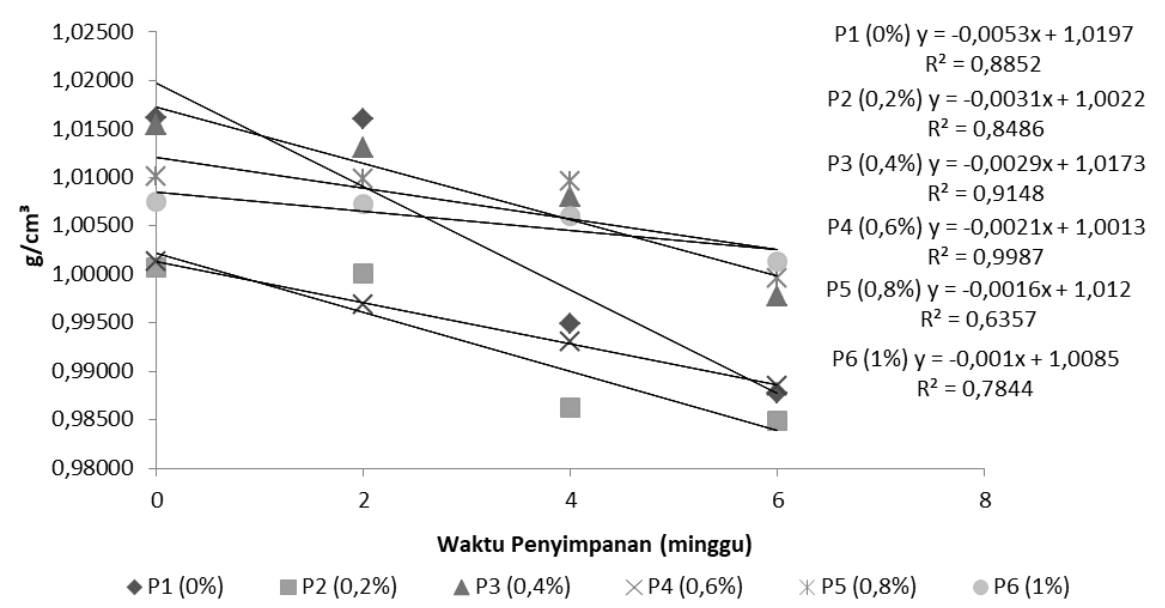

Gambar 3. Grafik bobot jenis krim kunyit-lidah buaya selama 6 minggu penyimpanan.

Gambar 3 menunjukkan bahwa bobot jenis pada sediaan krim kunyit-lidah buaya selama disimpan 6 minggu mengalami penurunan. Nilai awal bobot jenis pada minggu ke-0 berkisar antara 1,017-0,992 $\mathrm{g} / \mathrm{cm}^{3}$ sedangkan pada minggu ke- 6 berkisar antara 1,001-0,985 g/ $\mathrm{cm}^{3}$. Namun dari hasil penelitian ini diperoleh bahwa meskipun mengalami penurunan nilai bobot jenis pada semua perlakuan selama penyimpanan minggu ke-6 masih memenuhi standart SNI yaitu berkisar antara $0,95-1,05 \mathrm{~g} / \mathrm{cm}^{3}$. Sedangkan hasil regresi linier parameter bobot jenis krim kunyit-lidah buaya disajikan pada Tabel 4.

Tabel 4. Persamaan regresi linier parameter bobot jenis krim kunyit-lidah buaya.

\begin{tabular}{ccc}
\hline Perlakuan & Persamaan Regresi & Determinan $\left(\mathrm{R}^{2}\right)$ \\
\hline P1 $(0 \%)$ & $\mathrm{y}=-0,0053 \mathrm{x}+1,0197$ & 0,8852 \\
P2 $(0,2 \%)$ & $\mathrm{y}=-0,0031 \mathrm{x}+1,0022$ & 0,8486 \\
P3 $(0,4 \%)$ & $\mathrm{y}=-0,0029 \mathrm{x}+1,0173$ & 0,9148 \\
P4 $(0,6 \%)$ & $\mathrm{y}=-0,0021 \mathrm{x}+1,0013$ & 0,9987 \\
P5 $(0,8 \%)$ & $\mathrm{y}=-0,0016 \mathrm{x}+1,012$ & 0,6357 \\
P6 $(1 \%)$ & $\mathrm{y}=-0,001 \mathrm{x}+1,0085$ & 0,7844 \\
\hline
\end{tabular}

Dapat dilihat dari Tabel 4 bahwa koefisien regresi parameter bobot jenis dari variabel lama penyimpanan (X) pada perlakuan
$\mathrm{P} 1(0 \%)$ yaitu $-0,0053, \mathrm{P} 2(0,2 \%)$ yaitu $0,0031, \mathrm{P} 3(0,4 \%)$ yaitu $-0,0029, \mathrm{P} 4(0,6 \%)$ yaitu $-0,0021, \mathrm{P} 5(0,8 \%)$ yaitu $-0,0016$ dan P6(1\%) yaitu -0,001 Dari hasil tersebut dapat diketahui bahwa semakin tingginya penambahan konsentrasi phenoxyethanol dalam sediaan krim kunyit-lidah buaya maka akan semakin menghambat laju kerusakan bobot jenis krim. Bobot jenis sediaan dipengaruhi oleh jumlah konsentrasi phenoxyethanol yang digunakan. Semakin kecil konsentrasi phenoxyethanol yang digunakan pada sediaan maka bobot jenis akan semakin kecil, hal ini mengakibatkan jumlah air pada formula krim semakin tinggi. Dari hasil persamaan regresi linier P6(1\%) merupakan perlakuan terbaik yang mampu bertahan 41 minggu sampai nilai bobot jenis yang memenuhi standar SNI.

Berdasarkan hasil analisis regresi linier P6 (1\%) yang merupakan perlakuan terbaik mempunyai nilai $\mathrm{R}^{2}$ sebesar 0,7844 yang menunjukkan bahwa $78,44 \%$ laju kerusakan dipengaruhi oleh konsentrasi phenoxyethanol dan sisanya dipengaruhi oleh variabel diluar yang diteliti. Hal yang mempengaruhi bobot jenis diluar variabel 
yang diteliti salah satunya faktor lingkungan yaitu suhu penyimpanan. Jika suhu penyimpanan terlalu tinggi dapat mengakibatkan zat yang terkadung dalam sediaan menguap sehingga bobot jenis dapat berkurang.

\section{Viskositas}

Uji viskositas ini bertujuan untuk mengetahuin kekentalan pada sediaan krim kunyit-lidah buaya. Nilai viskositas akan menyatakan besarnya hambatan suatu bahan cair untuk mengalir, jika nilai viskositas suatu bahan cair semakin tinggi maka sifat yang dimiliki semakin kental dan semakin sukar untuk mengalir (Amananti et al, 2020). Pagur et al. (2020) menyatakan bahnwa semakin tinggi nilai viskositas sediaan krim makan semakin baik tingkat kestabilan krim karena pergerakan partikel krim akan semakin terhambat. Nilai viskositas dapat dikatakan sesuai apabila memenuhi standard SNI 164399-1996 yang berkisar antara 2.000-50.000 cps. Nilai viskositas krim kunyit-lidah buaya selama penyimpanan 6 minggu dapat di lihat pada Gambar 4.

Gambar 4 menunjukkan bahwa nilai viskositas sediaan krim kunyit-lidah buaya setelah penyimpanan selama 6 minggu mengalami penurunan. Nilai awal viskositas pada minggu ke-0 berkisar antara 1300010000 cps sedangkan pada minggu ke-6 berkisar antara 11000-9200 cps. Namun dari hasil penelitian yang telah dilakukan nilai viskositas selama penyimpanan 6 minggu pada semua perlakuan masih memenuhi standar SNI yaitu berkisar antara 2000-50000 cps. Sedangkan hasil regresi linier parameter viskositas dapat dilihat pada Tabel 5.

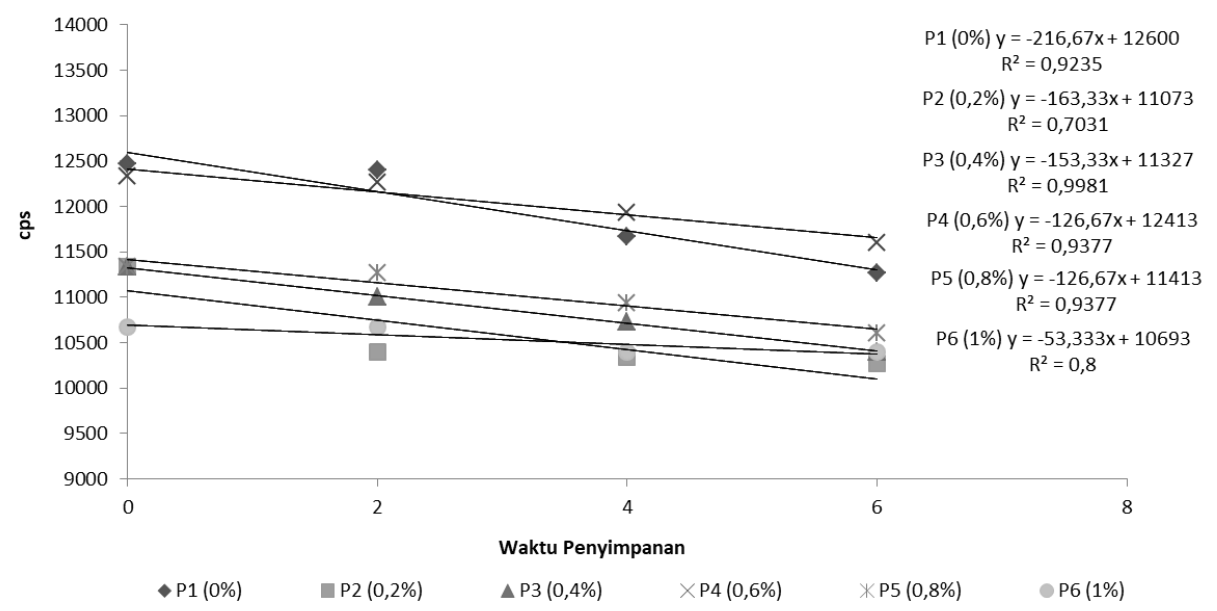

Gambar 4. Grafik viskositas krim kunyit-lidah buaya selama 6 minggu penyimpanan.

Tabel 5. Persamaan regresi linier parameter viskositas krim kunyit-lidah buaya.

\begin{tabular}{ccc}
\hline Perlakuan & Persamaan Regresi & Determinan $\left(\mathrm{R}^{2}\right)$ \\
\hline P1 $(0 \%)$ & $\mathrm{y}=-216,67 \mathrm{x}+12600$ & 0,9235 \\
P2 $(0,2 \%)$ & $\mathrm{y}=-163,33 \mathrm{x}+11073$ & 0,7031 \\
P3 $(0,4 \%)$ & $\mathrm{y}=-153,33 \mathrm{x}+11327$ & 0,9981 \\
P4 $(0,6 \%)$ & $\mathrm{y}=-126,67 \mathrm{x}+12413$ & 0,9377 \\
P5 $(0,8 \%)$ & $\mathrm{y}=-126,67 \mathrm{x}+11413$ & 0,9377 \\
P6 (1\%) & $\mathrm{y}=-53,333 \mathrm{x}+10693$ & 0,8 \\
\hline
\end{tabular}

Dapat dilihat dari Tabel 5 bahwa koefisien regresi parameter viskositas dari variabel lama penyimpanan (X) pada perlakuan $\mathrm{P} 1(0 \%)$ yaitu $-216,67, \mathrm{P} 2(0,2 \%)$ yaitu $-163,33, \mathrm{P} 3(0,4 \%)$ yaitu $-153,33$, $\mathrm{P} 4(0,6 \%)$ yaitu $-126,67, \mathrm{P} 5(0,8 \%)$ yaitu 126,67 dan P6(1\%) yaitu -53,333. Dari hasil tersebut dapat diketahui bahwa semakin tingginya penambahan konsentrasi phenoxyethanol dalam sediaan krim kunyit- 
lidah buaya maka akan semakin menghambat laju kerusakan viskositas krim. Hal ini dikarenakan bobot jenis berbanding lurus dengan viskositas. Semakin tingginya nilai bobot jenis pada perlakuan maka semakin tinggi pula nilai viskositasnya.

Berdasarkan hasil analisis regresi linier P6 (1\%) yang merupakan perlakuan terbaik mempunyai nilai $\mathrm{R}^{2}$ sebesar 0,8 yang menunjukkan bahwa $80 \%$ laju kerusakan dipengaruhi oleh konsentrasi phenoxyethanol dan sisanya dipengaruhi oleh variabel diluar yang diteliti. Penurunan nilai viskositas juga dipengaruhi oleh kenaikan ukuran diameter partikel yang menyebabkan luas permukaan semakin kecil sehingga viskositas menjadi turun. Ukuran diameter partikel meningkat disebabkan karena penyimpanan pada temperature yang tinggi yang mempengaruhi jarak antar atom menjadi renggang (Dewi et al, 2014).
Uji total fenol pada sediaan krim kunyit- Uji total fenol pada sediaan krim kunyit-lidah buaya ini bertujuan untuk mengetahui jumlah fenol yang terkandung dalam sediaan. Salah satu bahan aktif yang terkandung pada kunyit dan lidah buaya yaitu senyawa fenolik yang berperan sebagai antioksidan berfungsi untuk anti aging. Nilai total fenol krim kunyit-lidah buaya selama 6 minggu penyimpanan dapat dilihat pada Gambar 5.

Gambar 5 menunjukkan bahwa kandungan fenolik pada sediaan krim kunyitlidah buaya selama penyimpanan 6 minggu mengalami penurunan. Nilai awal total fenol pada minggu ke-0 berkisar antara 7,52827$8,90883 \mathrm{mg}$ GAE/g sedangkan pada minggu ke-6 berkisar antara5,62351-6,78748 mg GAE/g. Sedangkan hasil regresi linier parameter total fenol dapat dilihat pada Tabel 6.

\section{Total Fenol}

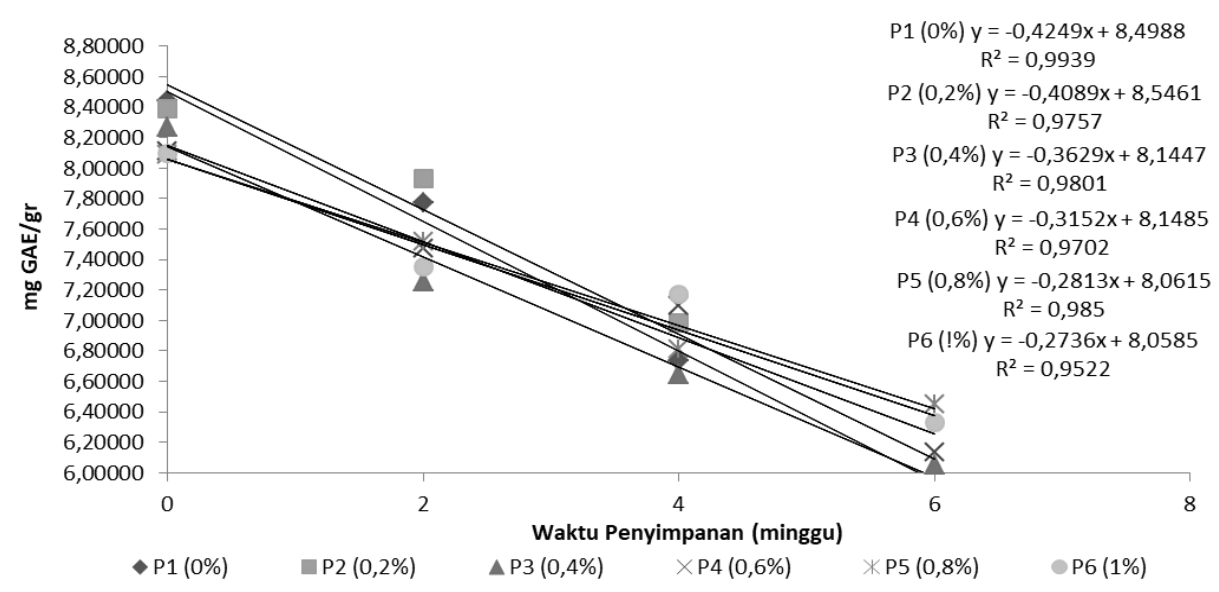

Gambar 5. Grafik total fenol krim kunyit-lidah buaya selama 6 minggu penyimpanan.

Tabel 6. Persamaan regresi linier parameter total fenol krim kunyit-lidah buaya.

\begin{tabular}{ccc}
\hline Perlakuan & Persamaan Regresi & Determinan $\left(\mathrm{R}^{2}\right)$ \\
\hline P1 $(0 \%)$ & $\mathrm{y}=-0,4249 \mathrm{x}+8,4988$ & 0,9939 \\
P2 $(0,2 \%)$ & $\mathrm{y}=-0,4089 \mathrm{x}+8,5461$ & 0,9757 \\
P3 $(0,4 \%)$ & $\mathrm{y}=-0,3629 \mathrm{x}+8,1447$ & 0,9801 \\
P4 $(0,6 \%)$ & $\mathrm{y}=-0,3152 \mathrm{x}+8,1485$ & 0,9702 \\
P5 $(0,8 \%)$ & $\mathrm{y}=-0,2813 \mathrm{x}+8,0615$ & 0,985 \\
P6 (1\%) & $\mathrm{y}=-0,2736 \mathrm{x}+8,0585$ & 0,9522 \\
\hline
\end{tabular}

Dapat dilihat dari Tabel 6 bahwa koefisien regresi parameter total fenol dari variabel lama penyimpanan (X) pada perlakuan $\mathrm{P} 1(0 \%)$ yaitu $-0,4249, \mathrm{P} 2(0,2 \%)$ yaitu -0,4089, P3(0,4\%) yaitu $-0,3629$, $\mathrm{P} 4(0,6 \%)$ yaitu $-0,3152, \mathrm{P} 5(0,8 \%)$ yaitu 0,2813 dan P6(1\%) yaitu -0,2736. Dari hasil tersebut dapat diketahui bahwa semakin 
tingginya penambahan konsentrasi phenoxyethanol dalam sediaan krim kunyitlidah buaya maka akan semakin menghambat penurunan total fenol krim. Phenoxyethanol mengandung fenol, yang memiliki kemampuan untuk menghambat aktivitas fagositik

(Lawrence JC, et al, 1982). Maka dari itu semakin tinggi konsentrasi phenoxyetanol yang di tambahkan semakin tinggi pula kadar fenol pada sediaan.

Berdasarkan hasil analisis regresi linier P6 (1\%) yang merupakan perlakuan terbaik mempunyai nilai $\mathrm{R}^{2}$ sebesar 0,9522 yang menunjukkan bahwa 95,22\% laju kerusakan dipengaruhi oleh konsentrasi phenoxyethanol dan sisanya dipengaruhi oleh variabel diluar yang diteliti.Penurunan kadar fenolik mengalami oksidasi selama penyimpanan yang di karenakan fenol memiliki sifat yang cenderung asam sehingga melepas ion $\mathrm{H}^{+}$dari gugus hidroksilnya (Sari,
2012). Devi et al (2019) menyatakan bahwa senyawa fenol merupakan senyawa yang akan teroksidasi dengan adanya cahaya, panas dan oksigen.

\section{Angka Lempeng Total (ALT)}

Uji angka lempeng ttotal (ALT) ini bertujuan untuk mennghitung jumlah koloni mikroba baik bakteri maupun jamur yang terdapat pada ediaan krim kunyit-lidah buaya. Pada uji angka lempeng total (ALT) ini dilakukan dengan menggunakan metode spread plate (cawan sebar). Nilai uji ALT krim kunyit-lidah buaya selama 6 minggu penyimpanan dapat dilihat pada Gambar 6 .

Gambar 6 menunjukkan bahwa hasil ALT pada sediaan krim kunyit-lidah buaya selama penyimpanan 6 minggu mengalami kenaikan pertumbuhan mikroba setiap 2 minggu. Sedangkan hasil regresi linier parameter ALT krim kunyit-lidah buaya dapat dilihat pada Tabel 7.

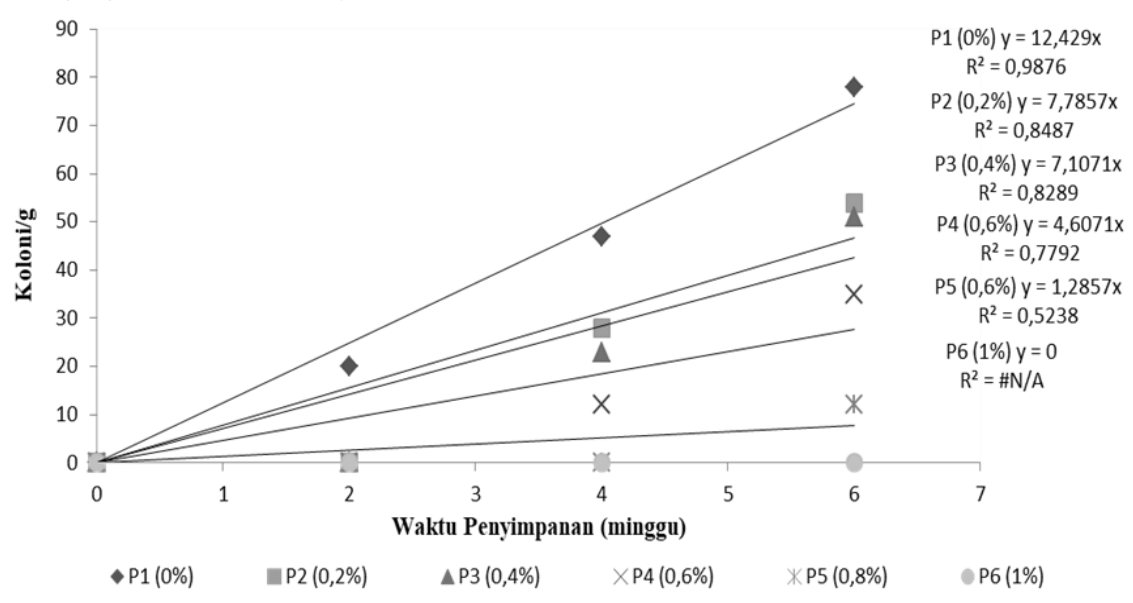

Gambar 6. Grafik ALT krim kunyit-lidah buaya selama 6 minggu penyimpanan.

Tabel 7. Persamaan regresi linier parameter angka lempeng total (ALT) krim kunyit-lidah buaya.

\begin{tabular}{ccc}
\hline Perlakuan & Persamaan Regresi & Determinan $\left(\mathrm{R}^{2}\right)$ \\
\hline P1 $(0 \%)$ & $\mathrm{y}=12,429 \mathrm{x}-2,9$ & 0,9876 \\
P2 $(0,2 \%)$ & $\mathrm{y}=7,7857 \mathrm{x}-8$ & 0,8487 \\
P3 $(0,4 \%)$ & $\mathrm{y}=7,1071 \mathrm{x}-7,9$ & 0,8289 \\
P4 $(0,6 \%)$ & $\mathrm{y}=4,6071 \mathrm{x}-5,8$ & 0,7792 \\
P5 $(0,8 \%)$ & $\mathrm{y}=1,2857 \mathrm{x}-2,4$ & 0,5238 \\
P6 $(1 \%)$ & $\mathrm{y}=0$ & 0 \\
\hline
\end{tabular}

Dapat dilihat dari Tabel 7 bahwa koefisien regresi parameter bobot jenis dari variabel lama penyimpanan (X) pada perlakuan $\mathrm{P} 1(0 \%)$ yaitu $-13,05, \mathrm{P} 2(0,2 \%)$ yaitu $-9,5, \mathrm{P} 3(0,4 \%)$ yaitu $-8,8, \mathrm{P} 4(0,6 \%)$ yaitu $-5,85, \mathrm{P} 5(0,8 \%)$ yaitu $-1,8$ dan $\mathrm{P} 6(1 \%)$ yaitu 0 . Hal ini menunjukkan bahwa perlakuan $\mathrm{P} 1(0 \%)$ mengalami kerusakan paling cepat perminggunya di bandingkan konsentrasi lainnya. Sedangkan perlakuan 
P6(1\%) belum mengalami pertumbuhan mikroba selama penyimpanan 6 minggu. Dari hasil persamaan regresi linier P6(1\%) merupakan perlakuan terbaik dan di perkirakan perlakuan P6 dengan penambahan phenoxyethanol $1 \%$ ini mampu menghambat mikroba hanya sampai minggu ke-6. Hal ini sesuai dengan penelitian Ramadhoni (2016) yang menyatakan bahwa perlakuan konsentrasi terbaik pada phenoxyethanol sebesar $1 \%$ dan dikombinasikan dengan hyamin $0,6 \%$. Dari hasil penelitian yang telah dilakukan menunjukkan bahawa phenoxyethanol tidak cukup kuat untuk menghambat pertumbuhan bakteri pada sediaan krim. Lowe dan Southern (1994) menyatakan bahwa phenoxyethanol merupakan pengawet yang tidak bisa berdiri sendiri maka dari itu perlu adanya pengawet lain yang mampu bekerja secara efektif bersamaan dengan phenoxyethanol, namun dari segi keamanan phenoxyethanol merupakan bahan pengawet yang paling aman di antara jenis pengawet lain. Pada hasil yang di dapatkan sediaan krim kunyit lidah buaya hanya perlakuan P6(1\%) yang masih memenuhi standard SNI karena belum melebihi $10^{2}$ koloni/gram pada minggu ke 6 .

\section{Angka Kapang Khamir (AKK)}

Uji angka kapang khamir (AKK) bertujuan untuk mengetahui adanya cemaran fungsi pada sediaan krim kunyit-lidah buaya. Nilai AKK krim kunyit-lidah buaya selama 6 minggu penyimpanan dapat dilihat pada Gambar 7.

Gambar 7 menunjukkan bahwa hasil AKK pada sediaan krim kunyit-lidah buaya selama penyimpanan 6 minggu mengalami kenaikan pertumbuhan mikroba. Banyaknya bakteri yang tumbuh juga dipengaruhi oleh proses pembuatan krim yang kurang steril serta proses pensterilan bahan pembuatan krim pada waterbath yang kurang maksimal. Dreno et al (2019) menyatakan bahwa phenoxyethanol ini efektif menghambat bakteri gram positive dan gram negative terutama pada bakteri Staphylococcus aeureus. Sedangkan hasil regresi linier parameter AKK krim kunyit-lidah buaya dapat dilihat pada Tabel 8.

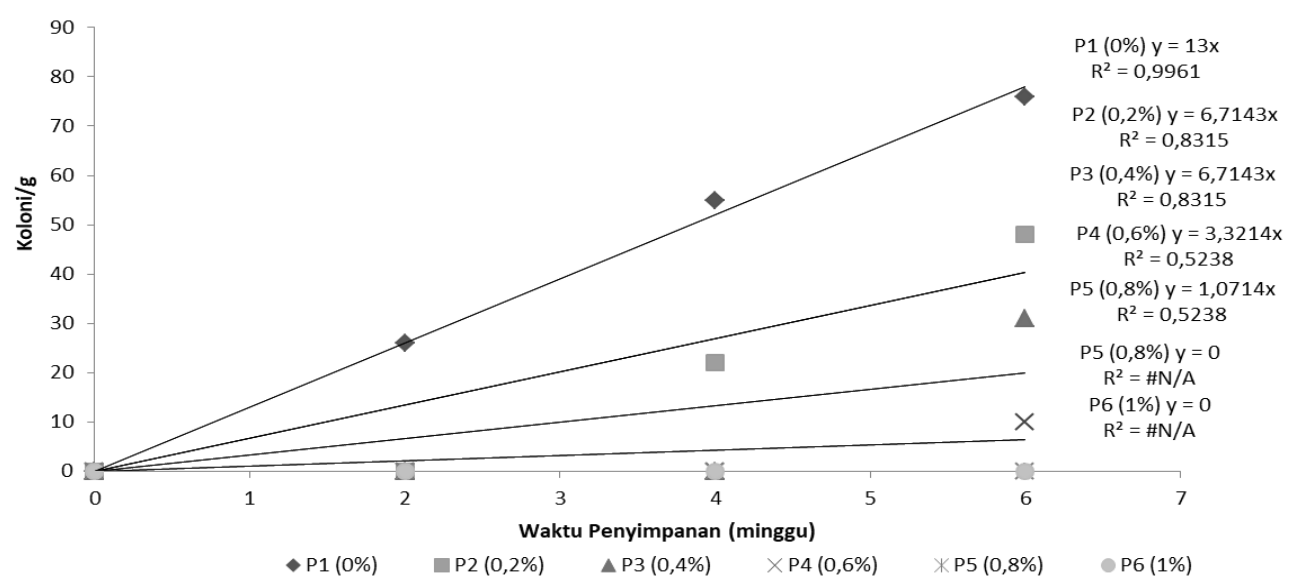

Gambar 7. Grafik AKK krim kunyit-lidah buaya selama 6 minggu penyimpanan.

Tabel 8. Persamaan regrsi linier parameter angka kapang khamir (AKK) krim kunyit-lidah buaya.

\begin{tabular}{ccc}
\hline Perlakuan & Persamaan Regresi & Determinan $\left(\mathrm{R}^{2}\right)$ \\
\hline P1 $(0 \%)$ & $\mathrm{y}=13 \mathrm{x}+0,7$ & 0,9961 \\
P2 $(0,2 \%)$ & $\mathrm{y}=6,7143 \mathrm{x}-7,4$ & 0,8315 \\
P3 $(0,4 \%)$ & $\mathrm{y}=3,3214 \mathrm{x}-6,2$ & 0,5238 \\
P4 $(0,6 \%)$ & $\mathrm{y}=1,0714 \mathrm{x}-2$ & 0,5238 \\
P5 $(0,8 \%)$ & $\mathrm{y}=0$ & 0 \\
P6 $(1 \%)$ & $\mathrm{y}=0$ & 0 \\
\hline
\end{tabular}


Dapat dilihat dari Tabel 8 bahwa koefisien regresi parameter bobot jenis dari variabel lama penyimpanan (X) pada perlakuan $\mathrm{P} 1(0 \%)$ yaitu $-12,85, \mathrm{P} 2(0,2 \%)$ yaitu $-8,3, \mathrm{P} 3(0,4 \%)$ yaitu $-4,65, \mathrm{P} 4(0,6 \%)$ yaitu $-1,5, \mathrm{P} 5(0,8 \%)$ yaitu 0 dan $\mathrm{P} 6(1 \%)$ yaitu 0 . Hal ini menunjukkan bahwa perlakuan $\mathrm{P} 1(0 \%)$ mengalami kerusakan paling cepat perminggunya di bandingkan konsentrasi lainnya. Sedangkan perlakuan P5(0,8\%) dan P6(1\%) belum mengalami pertumbuhan mikroba selama penyimpanan 6 minggu. Dari hasil persamaan regresi linier P5(0,8\%) dan P6(1\%) merupakan perlakuan terbaik dan di perkirakan dengan penambahan phenoxyethanol $0,8 \%$ dan $1 \%$ ini mampu menghambat mikroba hanya sampai minggu ke-6.

\section{KESIMPULAN DAN SARAN}

\section{Kesimpulan}

Berdasarkan penelitian yang telah dilakukan maka dapat disimpulkan beberapa hal sebagai berikut:

1. Nilai laju kerusakan laju kerusakan krim kunyit-lidah buaya terhadap konsentrasi phenoxyethanol setelah 6 minggu penyimpanan pada konsentrasi $0 \%$ mengalami laju kerusakan yang paling tinggi dan semakintingginya konsentrasi phenoxyethanol yang ditambahkan laju kerusakannya semakin menurun.

2. Berdasarkan hasil analisis regresi linier sederhana perlakuan terbaik yaitu P6 dengan penambahan pengawet phenoxyethanol $1 \%$ yang mampu menghambat laju kerusakan karakteristik krim kunyit-lidah buaya lebih baik dari pada perlakuan lainnya dengan nilai homogen, $\mathrm{pH} 5$, bobot jenis 1,00130 $\mathrm{g} / \mathrm{cm}^{3}$, viskositas $10400 \mathrm{cps}$, total fenol 6,33176 mg GAE/g, ALT 0 koloni/g dan AKK 0 koloni/g.

\section{Saran}

Perlu dilakukan penelitian lebih lanjut mengenai penambahan pengawet phenoxyethanol dengan kombinasi pengawet lain agar lebih efektif dalam menghambat pertumbuhan bakteri pada sediaan krim kunyit-lidah buaya.

\section{DAFTAR PUSTAKA}

Amananti, W. dan Riyanta, A. B. 2020. Karakteristik fisik sediaan foot sanitizer spray kombinasi ekstrak biji kopi (Coffea) dan rimpang jahe (Zingiber officinale) dengan variansi kecepatan dan waktu pengadukan. Jurnal Ilmiah Manuntung. 6(1).

Devi, I. G. A. S. K., Mulyani, S., \& Suhendra, L. 2019. Pengaruh Nilai HydrophileLiphophile Balance (HLB) dan Jenis Ekstrak terhadap Karakteristik Krim Kunyit-Lidah Buaya (Curcuma domestica val.-Aloe Vera). Jurnal Ilmiah Teknologi Pertanian Agrotechno. 4(2).

Dewi, R., Anwar, E. dan Yunita K. S. 2014. Uji stabilitas fisik formula krim yang mengandung kacang kedelai (Glycine max). Pharmaceutical Science \& Research. 1(3):5.

Dreno, B., T. Zuberbier, C. Gelmetti, G. Gontijo, and M. Marinovich. 2019. Safety review of phenoxyethanol when used as a preservative in cosmetics. Journal of the European Academy of Dermatology and Venereology. 33: 1524.

Erungan, A. C., Sri, P., dan Syeni, B. D. 2009. Aplikasi karaginan dalam pembuatan skin lotion. Jurnal Pengolahan Hasil Perikanan Indonesia. 12(2).

Indrawati, T. dan Dovita, E. 2013. Formulasi dan uji stabilitas sampo antiketombe yang mengandung perasan buah jeruk 
nipis (Citrus aurantifolia) dengan pengental HPMC. Program Studi Farmasi.

Kim, Tae Hwan, Min Gi Kim, Min Gyu Kim, Beom Soo Shin, Kyu Bong Kim, Jong Bong Lee, Soo Heui Paik, and Sun Dong Yoo. 2015. Simultaneous determination of phenoxyethanol and its major metabolite, phenoxyacetic acid, in rat biological matrices by lc$\mathrm{ms} / \mathrm{ms}$ with polarity switching: application to adme studies. Talanta. Vol 144.

Lawrence, J. C. Cason, J. S. dan Kidson, A. 1982. Evaluation of phenoxetolchlorhexidine cream as a prophylactic antibacterial agent in burns. The Lancet.

Lowe, I. dan Southern, J. 1994. The antimicrobial activity of phenoxyethanol in vaccines. Latters in Applied Microbiology. 18(2).

Mulyani, S. 2017. Sinergisme Antioksidan Kunyit dan Daun Asam (Curcuma domestica Val. - Tamarindus indica L.) Sebagai Bahan Aktif Krim. Disertasi. Fakultas Pertanian Universitas Udayana, Denpasar.

Morsy, E. M. 1991. The final technical report of aloe vera: stabilization and processing for the cosmetics beverage and food industries. Aloe Industry and Technology Institute. Phoenix, USA.

Natalie, A., Mulyani, S dan Admadi, B. 2017. Hubungan lama simpan dengan karakteristik mutu pada beberapa formulasi krim ekstrak kunyit (Curcuma domestica val). Jurnal Rekayasa dan Manajemen Agroindustri. 5(4).

Pagur, Y. W., Mulyani, S. dan Suhendra, L.
2020. Pengaruh penambahan ekstrak kulit buah naga (Hylocereus polyrhizus) terhadap karakteristik krim kunyit dan daun asam. Jurnal Rekayasa dan Manajemen Agroindustri. 8(4).

Prayitno, D. 2017. Pengaruh konsentrasi pengawet kombinasi etil heksil, gliserin dan phenoxyethanol terhadap karakteristik, stabilitas fisiska $\mathrm{pH}$ water based pomade yang mengandung ekstrak aloe vera.

Romadhoni, R. R. 2016. Pengaruh pemberian 2-phenoxyethanol dan hyamin terhadap mikroba uji dalam vaksin hexavalent. PhD Thesis.

Rowe, R. C., P.J. Sheskey, dan M.E. Quinn. 2009. Handbook of pharmaceutical excipients sixth edition. Pharmaceutical Press, London.

Juwita, A. P., Yamlean, P., dan Edy, H. J. 2013. Formulasi krim ekstrak etanol daun lamun (Syringodium isoetifolium). Jurnal Ilmiah Farmasi. 2(2).

Sari, B. P. S. 2006. Pengaruh penambahan tween 80 terhadap stabilitas piroksikam dalam larutan. Skripsi. Dipublikasikan. Fakultas Farmasi Airlangga, Surabaya.

Supriatna, D. N., Zaini, M. dan Mustofa F. H. 2015. Sistem pesediaan komponen pada mesin cetak berdasarkan laju kerusakan di PT. Karya Kita. Jurnal Teknik Industri Itenas. 3(3).

Syamsuni, H. 2006. Farmasetika dasar dan hitungan farmasi. Jakarta : EGC.

Wahyuni. 2019. Efektivitas pengawet dan respon panelis penggunaan masker wajah biji kakao kombinasi rumput laut. Balai Besar Industri Hasil Perkebunan : Makasar. 